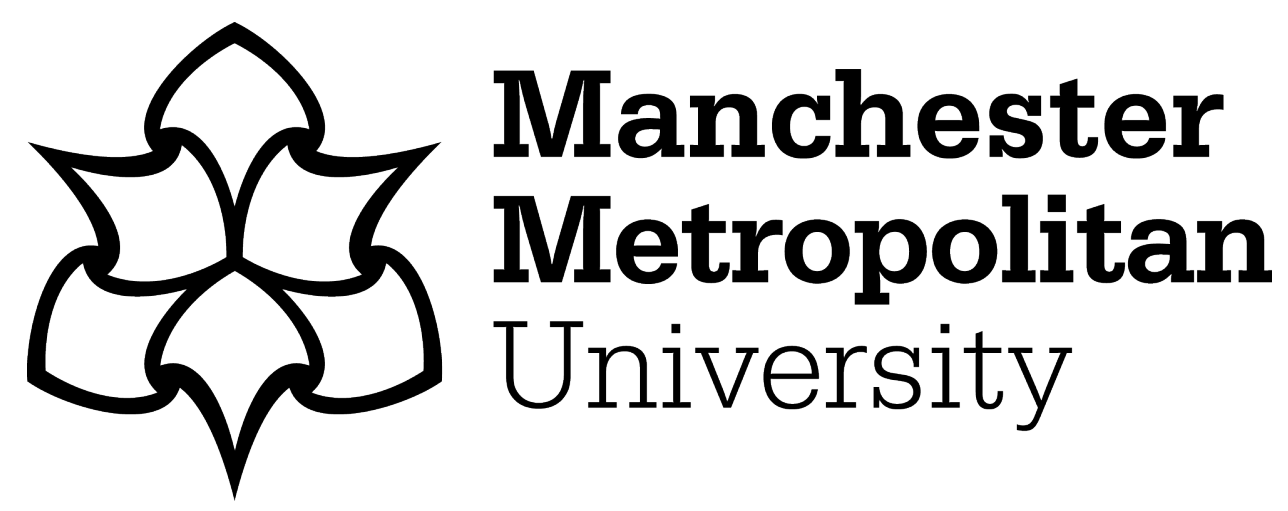

Ostashchenko, E ORCID logoORCID: https://orcid.org/0000-0002-48175753, Geelhand, P, Deliens, G and Kissine, M (2019) Struggling with alternative descriptions: Impaired referential processing in children with Autism Spectrum Disorder. Research in Autism Spectrum Disorders, 66. ISSN $1750-9467$

Downloaded from: https://e-space.mmu.ac.uk/627516/

Version: Accepted Version

Publisher: Elsevier

DOI: https://doi.org/10.1016/j.rasd.2019.101414

Usage rights: Creative Commons: Attribution-Noncommercial-No Derivative Works 4.0

Please cite the published version 


\section{Struggling with alternative descriptions: impaired referential processing in children with Autism Spectrum Disorder}

Ekaterina Ostashchenko ${ }^{1}$, Philippine Geelhand, Gaétane Deliens, Mikhail Kissine

ACTE/LaDisco \& UNI, Université libre de Bruxelles

Background: Children and adults with Autism Spectrum Disorder (ASD) show a tendency to preferentially rely on those referential descriptions that have previously been used by their conversational partner. However, such a tendency may become maladaptive in a situation of interaction with different partners who may introduce alternative lexical descriptions for the same referent. Methods: Six-year-old children with ASD, as well as mental- and verbal-age-matched typically developing (TD) children moved items on a touch-screen following instructions by an experimenter. During the entrainment phase, the experimenter introduced lexical descriptions for all the items. Then, either the original experimenter or a new partner, depending on the condition, used alternative descriptions for some items and kept the same descriptions for others. Accuracy and time to locate items were collected. Results: Relative to TD children, children with ASD had more difficulty in recognizing and interpreting referential descriptions when another description has been previously used. Whether a new description was introduced by a new or the original experimenter had no effect in any group. Conclusion: Referential processing in ASD is compromised by impaired ability to confront alternative conceptual perspectives. A potential executive source for these difficulties is discussed.

Keywords: Autism spectrum disorder, lexical entrainment, conceptual perspective, referential communication, perspective-taking, flexibility.

\section{Introduction}

Impaired communication is one of the core characteristics of Autism Spectrum Disorder (ASD). There is a wide consensus that deficits in social language use can lead to the idiosyncratic behaviors people with ASD frequently display in verbal exchanges, such as lack of narrative cohesion, difficulties in turn-taking, disfluencies, and restricted or unconventional vocabulary (Colle, Baron-Cohen, Wheelwright, \& Van Der Lely, 2008; Eigsti, Bennetto, \& Dadlani, 2007; Rapin \& Dunn, 2003). For the last fifteen years, these pragmatic deficits have standardly been attributed to impaired capacity to attribute mental states to other people (Baron-Cohen, Leslie, \& Frith, 1985; Eigsti, De Marchena, Schuh, \& Kelley, 2011). However, other authors propose that pragmatic deficits in ASD might arise from a deficit in executive

\footnotetext{
${ }^{1}$ Corresponding author at: ACTE -- Autism in Context: Theory and Experiment, Université Libre de Bruxelles, Avenue F.D. Roosevelt 50, B-1050 Brussels, Belgium. E-mail address:

Ekaterina.Ostashchenko@ulb.ac.be
} 
functions, which also mediate children's ability to successfully perform in false-belief tasks, standardly used to measure mentalizing skills (Kissine, 2012; Nilsen \& Fecica, 2011). The idea is that, in individuals with ASD, a limited ability to confront and navigate between multiple perspectives, caused by poor inhibitory control and/or cognitive flexibility, may make it challenging to simultaneously track one's own and the conversational partner's perspectives during conversations.

Communication requires processing information in a constantly changing environment. Not only do interlocutors need to track their conversational partners' perspectives, but they must also flexibly process different conceptual perspectives on a referent. Since a description is always selected from an indefinitely large space of alternatives, certain capacity for conceptual flexibility is needed. For instance, some speakers may use basic-level nouns-such as 'dog', while others may prefer 'animal' or 'terrier'. Labels reflect different conceptual perspectives as speakers' lexical choices single out specific aspects of the world. Therefore, in order to successfully map lexical meanings, listeners need to flexibly update conceptual perspective on the same object or event.

Additionally, as lexical choices made by conversational partners represent their unique perspectives on a given object or event, addressees may use their partners' perspectives as cues to facilitate lexical processing. For instance, it has been found that neurotypical adults expect that new partners will introduce new descriptions for the abstract images presented on the screen, but do not expect that partners with whom they already interacted would switch to new descriptions for no apparent reason (Brown-Schmidt, 2009; Metzing \& Brennan, 2003). Adults in these studies were faster to look at the object described by a new expression (e.g. the shiny cylinder) when a new partner used this description instead of one (e.g. the silver pipe) previously used by another partner. However, they were considerably slowed down when the alternative description (e.g. the shiny cylinder) was uttered by the original partner instead of the one she previously used (e.g. the silver pipe). It thus seems that adults spontaneously rely on their conversational partners perspectives to process lexical meaning.

It should be clear from the foregoing that flexibility in lexical processing may fail for at least two reasons. First, one may fail to inhibit a salient conceptual perspective in favor of another, contextually appropriate one. In such a case, lack of flexibility would consist in a perseveration 
on a particular conceptual perspective and would arise whenever a salient cognitive perspective - or referential description - has to be inhibited. Second, one may fail to systematically take into account one's conversational partner perspective. This difficulty would be closely associated with the development of social skills and may reveal lack of adequate communicative strategy.

Interestingly, typically developing (TD) young children may experience difficulties in flexibly processing alternative conceptual perspective. For instance, children under 5 were found to perform poorly in alternative naming task that required them to simultaneously apply two alternative descriptions (e.g. rabbit and bunny) to an object, even though they could identify the object with both descriptions when these were presented separately (Doherty \& Perner, 1998; Perner, Stummer, Sprung, \& Doherty, 2002). One possible explanation of children's resistance to alternative ways of naming one referent could be attributed to their reliance on 'mutual exclusivity' learning constraint (Markman \& Wachtel, 1988). While mutual exclusivity may provide young children with fast word-to-meaning mapping, it could also result in a tendency to consider a single label as being the only appropriate for an object. However, a mutual exclusivity bias is less likely to explain children's rejection of one label in favor of another when both words are already known to them; the difficulty rather seems to lie in the processing of the two descriptions when these are presented simultaneously. Another explanation of children's reluctance to use alternative descriptions is to appeal to immature executive functioning. Following this line of thought, young children are not able to confront several conceptual perspectives on the same object, because of difficulties in efficiently inhibiting the most salient one.

Notably, a tendency to perseverate on particular lexical items has also been attested in a corpus of conversions of adults with ASD (Perkins, Dobbinson, Boucher, Bol, \& Bloom, 2006). The analysis of lexical error patterns in this study revealed that individuals with ASD tended to repeat the words that had been used by their interlocutors in the preceding utterances. Whereas in many cases such a conversational strategy was appropriate, in some situations it turned maladaptive and revealed poor conceptual understanding of employed words.

Usually, communication is characterized by repetitive use of the descriptions by both interlocutors. Conversational partners tend to maintain the same lexical descriptions for repeatedly evoked referents throughout the entire exchange - a phenomenon known as 
'lexical entrainment' or 'alignment' (Brennan \& Clark, 1996; Pickering \& Garrod, 2004). However, it is still a matter of heated debate whether such a tendency to reuse previously established description is rooted in a low-level automatic priming mechanism or whether it arises from the expectations the interlocutors have about their partner's perspective. There is a relative consensus that adults take into account partner-specific cues during lexical processing. However there is no agreement as to whether this occurs as a supplementary, and hence optional layer of processing or whether comprehension of referential descriptions is entirely driven by the speakers' perspectives. According to the partner-independent account, other people's perspectives are processed optionally and allow interlocutors to revise their initially 'egocentric' interpretation to adjust their comprehension in a situation of referential ambiguity (Deliens, Antoniou, Clin, \& Kissine, 2017; Kronmüller \& Barr, 2007; Kronmüller, Noveck, Rivera, Jaume-Guazzini, \& Barr, 2017). On the contrary, according to the partner-specific theories of referential processing, interpretations of referential descriptions are rooted in common-ground representations, which constrain language interpretation processes early on (Brennan \& Clark, 1996; Brown-Schmidt, Yoon, \& Ryskin, 2015; Metzing \& Brennan, 2003).

This debate is pivotal for the understanding the communicative difficulties attested in ASD. If lexical entrainment is grounded in low-level automatic priming mechanisms, one may expect that individuals with ASD would show the same tendency to align with their partners on the lexical descriptions as their TD peers. It is also possible that individuals with ASD experience difficulties in switching away from the entrained descriptions, because of their tendency to perseverate on a primed and thus more salient conceptual perspective.

Available experimental evidence seems to corroborate with this hypothesis. Children and adults with ASD have been found to successfully align with their conversational partners on the lexical choices. Branigan et al. (2016) found that children with ASD spontaneously reused labels previously introduced by the experimenters during an interactive naming game. Furthermore, even when an experimenter described a picture with a 'dispreferred' label that is, with a label spontaneously produced less often than the alternative, 'preferred' one -, children with ASD tended to apply this dispreferred description shortly afterwards. Likewise, Slocombe et al. (2013) report that adults with ASD converged on the lexical choices 
with their partners and adopted rare labels (e.g. chapel rather than church), and even aligned with them on syntactic structure and spatial frame of reference.

That said, it is important to underscore that the tasks used in both Branigan et al. (2016) and Slocombe et al. (2013) had with very low demands on lexical flexibility: children were only asked to name objects depicted on a card following the same action by an experimenter; conflicting labels were not evoked during the task and hence no switching to an alternative description was required. It is likely that lexical alignment evidenced in such interactional contexts is not necessarily driven by considerations about common ground information and may simply arise from the automatic priming of the most recently introduced referential description. In a naturalistic conversational environment, however, mutual adaptation is associated not only with the lexical entrainment for recurring descriptions, but also with the ability to flexibly process alternative descriptions when they are used by a new partner or, for that matter, by the same speaker (for instance, to highlight a different perspective on the referent).

An experimental paradigm with partner's identity manipulation during referential communication task has been tested with adult participants with ASD by Nadig et al.(2015). In this study, participants had to describe tangram figures to experimental confederates over repeated rounds of a referential communication game. After several exchange rounds, a description for each figure was entrained (entrainment phase); next, either a new partner was introduced (new partner condition) or participants continued to describe figures to the same partner (same partner condition). During the entrainment phase adults with ASD and matched neuro-typical participants demonstrated similar patterns in lexical entrainment, becoming faster and using shorter versions of elaborated descriptions over the rounds. Participants in both groups were delayed by the introduction of a new partner. In neurotypical adults this delay was due to the necessity to negotiate once again a suitable description with a new partner. In the ASD group, some participants were also able to abandon the previously used referential descriptions and started to elaborate novel descriptions. These participants, however, needed more time than neurotypical participants to elaborate the novel description. Other participants with ASD displayed a maladaptive communicative pattern and kept using the entrained descriptions that could not have been known to new partners, thus showing perseveration on entrained descriptions and difficulty in elaborating alternatives. 
All the studies discussed above primarily explored how individuals with ASD produce referential descriptions. Less is known on how they process referential descriptions and whether they exhibit difficulties in grasping lexical meanings in a dynamic interactional context. In the study reported below, we ask whether children with ASD exhibit difficulty in flexibly processing alternative labels for previously described referents, and whether their referential processing is influenced by partner's identity. Two studies exploring processing of referential precedents by TD young children have reported sensitivity to partner-specific cues in referential processing (Graham, Sedivy, \& Khu, 2014; Matthews, Lieven, \& Tomasello, 2010). These studies employed experimental design similar to the study with adults by Metzing \& Brennan (2003) and investigated children's ability to process the shift to alternative conceptual perspective in the context of interaction with different partners. In Matthews et al. (2010), simple nouns were used to label referents (such as 'tree' or 'bush'), while in Graham et al. (2014) the referents were described with adjectival modifiers (such as 'striped ball' or 'purple ball'). A description that was used several times to label a referent during entrainement ('tree') was then replaced by an alternative expression ('bush') either by a new speaker or by the original speaker. In Graham et al. (2014), the only significant partner effect was found in processing the descriptions that remained the identical during and after entrainement: children were faster in visually locating referents that were referred to with the same expressions after entrainement with the same speaker compared to processing of these descriptions with a new partner. However, no evidence of partner-specific processeing of alternative descriptions has been reported in this study, neither for accuracy in children's performance nor for their gaze distribution. This result may be interpreted either as showing that 4-year-old children expect their partner to use the description that she or he has previosuly established, or else as showing low-level automatic facilitation in processing of the same expression uttered by the same speaker. To compare, in studies with adults, additionally to the same speaker advantage in processing of maintained precedents ${ }^{2}$ there has been found an advantage in processing of alternative descriptions by a new speaker. This partner-specific effect cannot by entirely attributed to the automatic memory effect and shows that adults expect that new partners will use alternative descriptions rather than maintain precedents

\footnotetext{
${ }^{2}$ The same-speaker advantage in processing of maintaned precedents has been detected in adults by Brown-Schmidt (2009), but not by Metzing \& Brennan (2003).
} 
elaborated with another partner. Moreover, an advantage in processing of the same describtion by the same speaker alone is not sufficient to claim partner-specific processing of referential precedents. It is therefore important to distinguish these two different effects in processing of referential precedents with different partners: a faster processing of reoccuring descriptions with the same partner and a faster processing of alternative descriptions with a new partner. Importantly, a difference score that was used in a study by Matthews et al. (2010) does not allow to differentiate between two possibile mechanisms explained above. It is therefore important to re-examine whether the common ground information guides lexical access in TD young children in an adult-like way by carefully analyzing whether their processing of alternative (and not only maintained descriptions) is affected by the partner condition.

In this paper, we explore how children with ASD process referential precedents in an interactive setting. The experimental design used in this study is analogous to the previous studies that reported partner-specific effects in referential processing in adults (BrownSchmidt, 2009; Metzing \& Brennan, 2003) and to the similar studies with TD children (Graham et al., 2014; Matthews et al., 2010). However, as just discussed, the interpretation of the results obtained in the latter studies with children is prone to ambiguity. Consequently, we adopted an analytical approach similar to the one used in studies with adults, which allowed us to specifically determine whether children with and without ASD expect the new partners to introduce new referential descriptions for the items that have been previously referred to with a different label by another partner.

A number of possible outcomes could be expected from our study with children with and without ASD. If children with ASD perseverate on a more salient conceptual perspective, one should expect a diminished accuracy and a delay in their processing of alternative descriptions, perhaps in both partner conditions (with the original and a new partner). If TD children do show sensitivity to common ground information in the processing of referential precedents, we might expect signs of the facilitation in processing of alternative descriptions with a new partner co-occurring with faster processing of maintained descriptions with the original partner. It is also reasonable to expect that children with ASD would fail to use partner-specific cues in referential processing. 
Instead of a classic comparison between typical and atypical populations, we adopted a dimensional approach, which focuses not only on detecting differences, but also on identifying similarities between typical and atypical development. It has been recently argued that such approaches may yield better understanding of both typical and atypical cognitive development, and, in our case, provide a nuanced model of referential processing (Graham \& Madigan, 2016). We pairwise matched children with ASD with two different groups of TD children, first according to their verbal level, and, second, according to their non-verbal IQ. TD children in the verbal-age-matched group are expected to be significantly younger than those in the mental-age-matched group, since preschoolers and primary school children with ASD are known to have lower rate of vocabulary growth. In addition to investigating the processing of broken precedents in ASD, this matching method allowed us to compare the impact of chronological age in speed and accuracy of referential comprehension between typical and autistic development.

\section{Materials and methods}

\section{Participants}

Twenty-two children with ASD were recruited to take part in this study. Parents provided written consent, and procedures were approved by the Ethics Committee of the Queen Fabiola Children's University Hospital. Diagnosis was confirmed by administration of the Autism Diagnostic Observation Schedule to the children (ADOS; Lord et al., 2000) and the Autism Diagnostic Interview-Revised to their parents (ADI-R; Lord, Rutter, \& Le Couteur, 1994). All children came from monolingual French speaking homes. Receptive vocabulary, measured by the French version of the Peabody Picture Vocabulary Test - Revised (Dunn L. M., 1993) was a proxy for verbal level. Non-verbal IQ was measured by the composite score of four intelligence subtests (Sequential Order, Form Completion, Classification and Analogies and Figure Ground) of the Leiter-3 (Roid, Miller, Pomplun, \& Koch, 2013), which is particularly suited to assess non-verbal cognitive abilities in populations with atypical development. All children included in the final sample were considered cognitively able, achieving IQ scores of 70 or above. Of the total sample of 22 children with ASD, only those participants who were younger than 8-years-old at the time of the testing and completed all sessions of the study were included in the present analyses, yielding a final sample size of 18 children in the ASD group. 
A receptive language delay is often reported in ASD. Since our task targeted referential processing, it was crucial to match the ASD group with TD children that would not be privileged in the task because of better receptive vocabulary abilities. Children were also matched on their non-verbal cognitive abilities, to compare performance of children in the ASD group with a group of TD children closer in chronological age. Participants with ASD (mean chronological age: 6.0, range 4.1 to 7.7 years) were pairwise matched to two distinct groups of TD children. The TD Verbal Age (VA) comparison group was determined by receptive vocabulary, based on the PPVT raw score. The TD Mental Age (MA) comparison group was based on non-verbal mental age, based on Leiter- 3 raw score (which converted into abilitylevel estimate, allowing to calculate a composite score). TD children were drawn from a larger sample recruited to validate the experimental paradigm. The groups were matched pairwise, so that each of the 18 participants with ASD was individually paired with one TD child of the same verbal age and one TD of the same mental age.

ANOVA comparisons between groups were conducted using standardized Peabody and Leiter-3 scores. Since children in the ASD group are significantly older than children in both matched groups, they expectedly underperformed children in those groups on the standardized scores (see Table 1).

\begin{tabular}{|c|c|c|c|c|c|c|c|}
\hline & $\begin{array}{c}A S D \\
(n=18)\end{array}$ & $\begin{array}{c}\text { Mental age } \\
\text { match } \\
(M A) \\
(n=18)\end{array}$ & $\begin{array}{c}\text { Verbal age } \\
\text { match (VA) } \\
\quad(n=18)\end{array}$ & $\begin{array}{l}\text { One-way } \\
\text { ANOVA }\end{array}$ & \multicolumn{3}{|c|}{ Significant $t$ tests $(p<.05)$} \\
\hline & $\begin{array}{c}\text { Mean } \\
(S D) \\
\text { range }\end{array}$ & $\begin{array}{l}\text { Mean } \\
(S D) \\
\text { range }\end{array}$ & $\begin{array}{c}\text { Mean } \\
(S D) \\
\text { range }\end{array}$ & & $A S D-M A$ & $A S D-V A$ & $M A-V A$ \\
\hline $\begin{array}{c}\text { Chronological } \\
\text { age }\end{array}$ & $\begin{array}{c}6.08 \\
(1.08) \\
4.1-7.7\end{array}$ & $\begin{array}{c}5.15 \\
(0.98) \\
3.11-6.4\end{array}$ & $\begin{array}{c}4.01 \\
(0.95) \\
3.1-6.2\end{array}$ & $\begin{array}{c}F=23.81, \\
p<.001\end{array}$ & $A S D>M A$ & $A S D>V A$ & $\mathrm{MA}>\mathrm{VA}$ \\
\hline $\begin{array}{c}\text { Non-verbal IQ } \\
\text { score (raw) }\end{array}$ & $\begin{array}{c}53.28 \\
(9.78) \\
34.0-73.0\end{array}$ & $\begin{array}{c}53.94 \\
(10.71) \\
35.0-79.0\end{array}$ & $\begin{array}{c}28.94 \\
(6.15) \\
36.0-80.0\end{array}$ & $\begin{array}{c}F=1.59 \\
p=0.21\end{array}$ & & & \\
\hline $\begin{array}{l}\text { Vocabulary } \\
\text { score (raw) }\end{array}$ & $\begin{array}{c}35.16 \\
(21.86) \\
13.0-88.0\end{array}$ & $\begin{array}{c}58.47 \\
(23.27) \\
20.0-85.0\end{array}$ & $\begin{array}{c}37.11 \\
(21.07) \\
14.0-86.0\end{array}$ & $\begin{array}{l}F=6.38, \\
p=.003\end{array}$ & $\mathrm{ASD}<\mathrm{MA}$ & & $\mathrm{MA}>\mathrm{VA}$ \\
\hline $\begin{array}{c}\text { Non-verbal IQ } \\
\text { score } \\
\text { (standardized) }\end{array}$ & $\begin{array}{c}85.88 \\
(10.18) \\
70.0-107.0\end{array}$ & $\begin{array}{c}93.88 \\
(7.80) \\
81.0-118.0\end{array}$ & $\begin{array}{c}95.83 \\
(14.01) \\
74.0-108.0\end{array}$ & $\begin{array}{c}F=4.30 \\
p<.01\end{array}$ & $\mathrm{ASD}<\mathrm{MA}$ & $A S D<V A$ & \\
\hline
\end{tabular}




\begin{tabular}{|c|c|c|c|c|c|c|}
\hline $\begin{array}{l}\text { Vocabulary } \\
\text { score } \\
\text { (standardized) }\end{array}$ & $\begin{array}{c}74.23 \\
(22.83) \\
40.0-115.0\end{array}$ & $\begin{array}{c}106.94 \\
(21.11) \\
77.0-131.0\end{array}$ & $\begin{array}{c}95.83 \\
(14.01) \\
77.0-117.0\end{array}$ & $\begin{array}{c}F=13.06, \\
p<.001\end{array}$ & $A S D<M A$ & $A S D<V A$ \\
\hline
\end{tabular}

Table1. Descriptive statistics broken down by three groups (ASD = Autism Spectrum Disorder, $M A=$ mental-age-matched TD children, VA = verbal-age-matched TD children)

Stimuli

We created a collaborative computerized task inspired by the paradigm used in Matthews et al. in a way to simplify data collection and diminish potential coding biases. We selected 8 pairs of labels, such that each pair could constitute an alternative label for the same entity from Manulex (Lété, Sprenger-Charolles, \& Colé, 2004) French database (see Table 2). Those entities could be referred to equally felicitously with two labels and thus corresponded to our 4 target items. A professional artist created two sets of 12 pictures, each consisting of:

- 4 pictures for items, referred to with two alternative labels during the task;

- 4 pictures for items, always referred to with the same label;

- 4 filler items, always referred to with the same label, but for which no measures were collected.

To ensure a similar level of visual salience among items, drawings were performed in such a way that no picture stood apart in the amount of detail, hue, intensity or color. Two sets of objects were created for a within-subject design, so that each child played with both sets of objects during two different sessions (see Table below).

\begin{tabular}{|l|l|l|}
\hline Items referred to with alternative & $\begin{array}{l}\text { docteur-médecin (doctor-physician) } \\
\text { peluche-nounours (cuddly toy- } \\
\text { teddybear) } \\
\text { feuille-papier (sheet-paper) } \\
\text { chaussures-bottes (shoes-boots) }\end{array}$ & $\begin{array}{l}\text { enfant-bébé (child-baby) } \\
\text { fenêtre-vitre (window-pane) }\end{array}$ \\
\hline $\begin{array}{l}\text { Items referred to with maintained } \\
\text { descriptions }\end{array}$ & $\begin{array}{l}\text { avion (plane) } \\
\text { sac-cartable (bag-satchel) }\end{array}$ \\
\hline fouris (mouse) & $\begin{array}{l}\text { train (train) } \\
\text { cheval (horse) }\end{array}$ & $\begin{array}{l}\text { lapin (rabbit) } \\
\text { téléphone (phone) } \\
\text { livre (book) }\end{array}$ \\
\hline $\begin{array}{l}\text { poisson (fish), étoile (star), verre } \\
\text { (glass), maison (house) }\end{array}$ & $\begin{array}{l}\text { vache (cow), voiture (car), chien } \\
\text { (dog), chat (cat) }\end{array}$ \\
\hline
\end{tabular}

Table 2. French labels used in set 1 and set 2, with English translations in brackets 
The task was created using Adobe Flash (C) with ActionScript 2.0. The test screen consisted in four groups of three drawings of items placed in each corner of the screen, and the drawing of a photo frame, placed beneath the drawing of a photo camera, in the centre of the screen with the camera button above (see Figure 1). Exactly two items could be placed within the photo frame. To move an item to the photo, frame, the child had to touch it first, and then the item moved to the photo frame. The child's task was to make a set of photos following instructions by an experimenter sitting behind her. Once two items were placed in the picture frame, a photo could be made by touching the camera button. If the choice of two objects in the photo frame was correct, viz. if it matched experimenter's instructions, the sound of a photoflash was produced; if the choice was incorrect, an error sound was produced and no photo could be taken. The script was run in Tobii studio software (version 3.5.6) as screen recording media element; all the clicks were recorded.

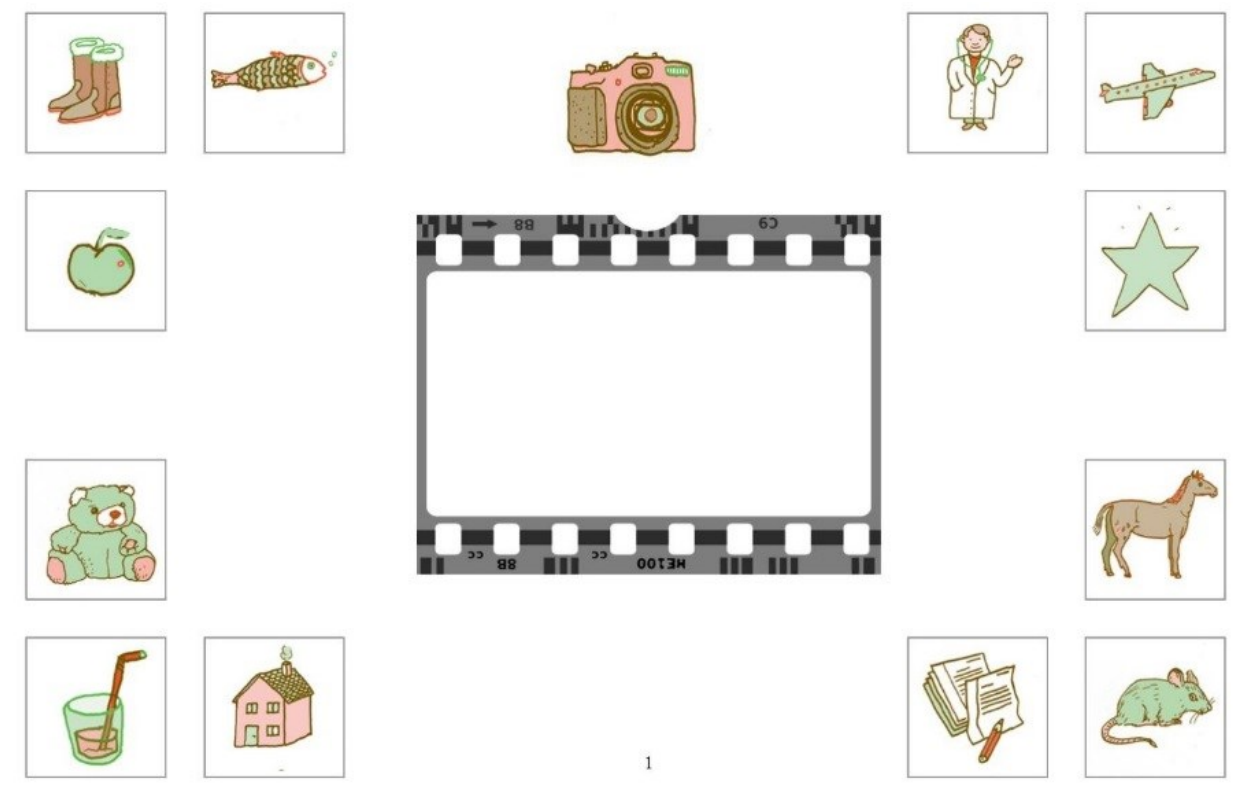

Fig 1. Screenshot of the starting screen for the set 1

Procedure

The experiment consisted of three sessions, each lasting around thirty minutes. During the first session, two experimenters were introduced to each child. One experimenter 
administered the Peabody and the other one, the two subtests of the Leiter-3, so that both experimenters were familiar to the child at the end of the first session.

In the second session, the child saw again the same experimenters. The session began by the administration of the remaining two subsets of the Leiter-3 (by the same experimenter as in the first session). Next, after some time of free play with both experimenters, one experimenter left the room with the phone of the other experimenter. The experimenter who stayed in the room showed the set of photos that she had on her electronic device and explained that the same photoset could be reproduced on the touchscreen display. After showing how to take photos on the screen, the experimenter asked if the child would like to play. When the child agreed, the first part of the experiment started. The experimenter began by telling the child: 'Now, we need to take a photo of the [first item], can you touch it?'. Once the child touched the first item, the experimenter went on: 'And now, we need [second item], can you touch it?'. Finally, when both items were located within the photo frame, the experimenter said: 'And now we can take a photo, touch the camera!'. Note that our instructions did not contain any spatial prepositions (e.g. next to, under or above). In this way, we avoided potential errors and delays linked to cognitive processing of spatial relations.

During the first entrainment part of the task session, the child made sixteen photos reflecting different combinations of pairs of items. Those combinations were created so that each target and non-target item was referred to with the same expression three times; the remaining 8 items were randomly selected from the list of fillers. Experimenters were instructed to pronounce the second label word at the exact moment when the previous item has been placed in the photo frame for the accuracy of collected reaction time.

Once sixteen photos were made, the first part of the session was over and the second experimenter came back. She explained that the first experimenter received several phone calls and probably should answer her phone. What happened next depended on the condition - New Partner or Same Partner - that was assigned to the set. In the New Partner condition, the first experimenter replied that she was waiting for important phone calls and should answer it. She asked whether the child would like to continue taking photos with the second experimenter and left the room after the child's approval. In the Same Partner condition, the first experimenter answered that she would like to call back later and would continue to play with the child. 
The second part of the session then began, with the same or the new experimenter depending on the condition - playing the same photo game. Eight photos in total were made in the second session. For each photo, the first named item was a filler, and the second alternated between target and non-target items. All target items were designated by the label different from the one used in the first training session (i.e. new label). In this way, each target and non-target object was always followed by a filler. This allowed us to eliminate any potential spillover effect between target and non-target items.

The disposition of the items on the screen in each set was kept constant throughout all trials to minimize the potential influence of individual variation in executive processing and visual and/or spatial perception on reaction times.

In this within-subject design, each child took part in two experimental sessions, one per condition (same vs. different partner), each session consisting in two parts (entrainment and test phase). Each experimental session was associated with one of the two sets of pictures, and with one of two conditions. The association between sessions, sets of pictures and conditions was evenly counterbalanced across participants.

It could be that some children are 'hyper-conventional', in the sense that they would perceive one of the two labels associated with a target as an intrinsically inaccurate description, independently of the rupture of lexical entrainment. To reduce this potential bias, labels for target items were also counterbalanced between the first and second parts of each set. For example, for half of the children assigned to set 1 , the picture of the physician in a white coat was referred to by médecin in the first part of the session and by docteur in the second part; this order was reversed for the second half of children assigned to set 1.

\section{Results}

\section{Data preparation}

First, we coded accuracy of children's referential processing that corresponded to the correct or incorrect choices of target and non-target items for the last occurrence of the corresponding item during the entrainment phase and during the test phase of each session.

Second, we extracted reaction times (RT) in the second part of each session, understood as the time needed to locate an item referred to by the experimenter. RTs were obtained by manually segmenting all screen recordings obtained in Tobii studio software. To generate 
these segments, we identified the onsets of each critical word, through visual and audio inspection of the corresponding sound waves in Praat (Boersma, 2001). Next, we tagged the time-points corresponding to this onset on screen recordings for all target and non-target items. Finally, we isolated all the segments between those tags and the corresponding clicks on the screen to analyze their length. Those values were positively skewed and were consequently log-transformed using the Box-Cox procedure (Box and Cox, 1964).

\section{Analyses}

We excluded from the analysis trials in which the experimenter erroneously used an entrained label instead of a new one (0.4\%), or the child was helped by an experimenter when she asked for a help and exceeded a 10s interval of self-reliant searching (1.7\%). We also excluded trials in which the child asked questions not related to the task and thus was delayed in her performance from RT analyses (1.8\%). The remaining 784 observations were analyzed in R (R Core Team, 2017) within the Ime4 package (Bates, Maechler, Bolker, \& Walker, 2015). The significance of a factor was analyzed by building it as fixed factor within a model and conducting log-likelihood comparisons of fit with otherwise identical models which excluded this factor (Baayen, Davidson, \& Bates, 2008).

We implemented mixed-effect models starting with a maximal, design-driven random effects structure including Order by-item and by-participant intercepts. To determine whether the ASD group exhibits a significant overall difficulty in the task relative to the two comparison groups (VA and MA), we contrast-coded the Group variable (ASD vs. two TD groups and VA vs. MA). In this way, we were able to calculate the parameters that capture potential differences between children with and without ASD. The intercept reported for this refitted model corresponds to the main effect of the group where VA and MA groups are the subtypes of a typically developing group.

First, we fitted the binomially distributed accuracy of children's responses in the entrainment phase (i.e. before any label and/or partner manipulation took place) within a general mixed effects model with Group as fixed factor. There was no significant Group effect on the accuracy score during the entrainment phase $\left(\chi^{2}(2)=2.30, p=0.30\right)$. Overall, children committed very few errors during the entrainment phase ( $2 \%$ across all groups). 
Next, we fitted accuracy of children's responses during the second phase (i.e. when the partner (same or new) maintained the precedent for non-target items and broke the precedent for target items) within a general mixed effect model with Group, Precedent (broken or maintained), and Partner's identity (same or new) as fixed effects. We also adjusted for the sample differences in chronological age, verbal and non-verbal IQ by including these variables as covariates in all tested models.

There was a significant effect of Group $\left(\chi^{2}(2)=11.44, p=.003\right)$ and of Precedent $\left(\chi^{2}(1)=11.46\right.$, $p<.001)$, but no interaction between Group and Precedent $\left(\chi^{2}(2)=1.78, p=0.41\right)$. No effect of Partner $\left(\chi^{2}(1)=0.66, p=0.41\right)$ and no interaction between Partner and Precedent $\left(\chi^{2}(1)=0.10\right.$, $p=0.74)$ and between Partner, Precedent and Group $\left(\chi^{2}(7)=4.00, p=0.78\right)$ were detected in all tested models. We failed to capture any evidence that erroneous referential choices made by children were associated with the identity of interactional partner: the probability of an error provoked by the modification of previously entrained conceptual perspective was thus independent of the interactional context (same vs. new partner).

\begin{tabular}{r|cccc} 
Effect & Estimate $(\beta)$ & $S E$ & z-value & $p$ \\
\hline Intercept (ASD group/ TD groups) & 2.95 & 2.03 & 1.45 & \\
Broken precedent & 2.00 & 0.55 & 3.62 & $<.001^{* * *}$ \\
Same Partner & 0.26 & 0.35 & 0.75 & 0.44 \\
Chronological age & -0.04 & 0.01 & -2.46 & $0.01^{*}$ \\
Verbal IQ & -0.03 & 0.01 & -3.50 & $<.001^{* * *}$ \\
Non-verbal IQ & -0.02 & 0.01 & -1.82 & 0.06 \\
ASD compared to both TD groups & 1.10 & 0.38 & 2.88 & $=.003^{* *}$ \\
VA compared to MA & 0.92 & 0.58 & 1.59 & 0.11 \\
Table 3. Fixed effects in a linear mixed effects model fitting accuracy of children's response \\
(parameters for a treatment coding of the Group factor) & &
\end{tabular}

However, as it can be seen from the summary of the model in Table 3, children in the ASD group underperformed both comparison groups. They displayed difficulty in switching to alternative descriptions even when the sample differences in chronological age, as well as in verbal and non-verbal IQ are controlled for. Mean accuracy score for Broken Precedents per Group and Condition are displayed in Fig. 2. 


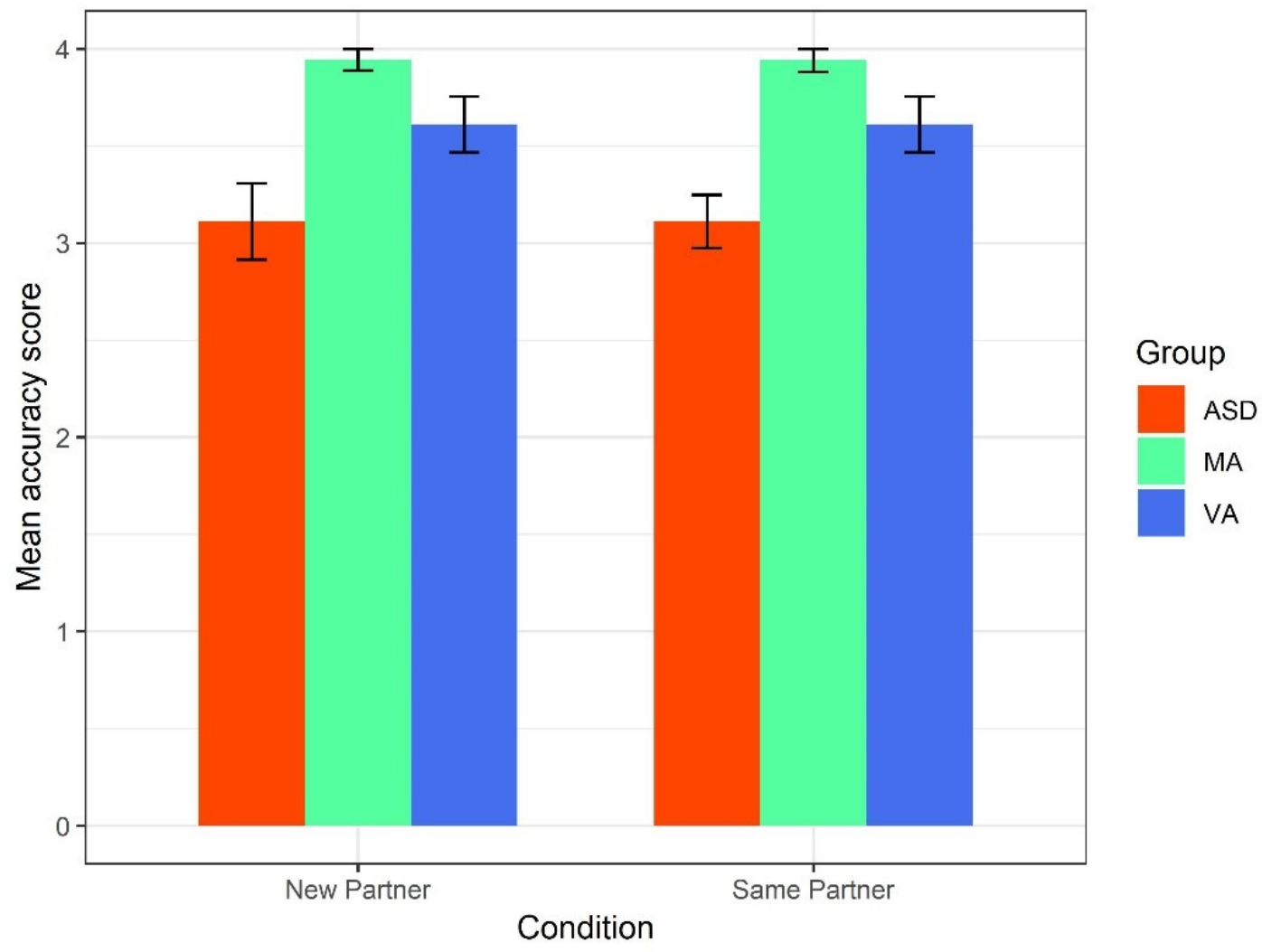

Figure 2. Mean accuracy score in reacting to Broken Precedents by Group (ASD=Autism Spectrum Disorder, $M A=$ mental-age matched TD children, $V A=$ verbal-age matched children), per Condition. Error bars represent SEM.

To further explore whether ASD children had difficulty in reacting to broken precedents, we performed an analysis of reaction times, using multilevel linear mixed models. We tested fixed effects of Group, Partner's identity, and Precedent (Table 4). We detected a significant main effect of Precedent $\left(\chi^{2}(1)=8.51, p=.003\right)$. Simple effects of Group $\left(\chi^{2}(2)=0.13, p=0.93\right)$ and of Partner's identity were not detected $\left(\chi^{2}(1)=0.02, p=0.87\right)$. A significant interaction between Group and Broken precedent indicated a between group difference in reaction to label's modification $\left(\chi^{2}(2)=21.56, p<.001\right)$. However, no interaction between Group, Partner's identity, and Precedent could be identified $\left(\chi^{2}(5)=7.28, p=0.20\right)$. Since Partner condition, Precedent and Group did not interact significantly, distribution probabilities of RTs in the ASD and TD groups were independent from the difference in integration of interactional context to the processing of broken precedents between ASD and TD children.

We then explored the interaction between Precedent and Group by performing post-hoc contrasts with Ismeans package, adopting the Tukey method for multiple comparisons (Lenth, 2016); the confidence level was set at 0.95 . Significant interaction between broken versus 
maintained precedent and group consisted in faster responses to broken precedents in the MA group compared to the VA group $(\beta=-0.29, S E=0.07, t=-3.68, p=.001)$. However, reaction to Broken precedent in the ASD group did not differ significantly neither from the distribution in the VA group $(\beta=-0.14, S E=0.08, t=-1.79, p=0.17)$ nor from the distribution in the $M A$ group $(\beta=0.14, \mathrm{SE}=0.07, \mathrm{t}=1.83, \mathrm{p}=0.16)$. The effects of the model with interaction between Precedent and Group are plotted in Figure 3.

\begin{tabular}{r|cccc} 
Effect & Estimate $(\beta)$ & $S E$ & $t$ & $p$ \\
\hline Intercept (ASD group/TD groups) & 8.64 & 0.30 & 28.38 & \\
Broken precedent & 0.17 & 0.05 & 3.54 & $.002^{* *}$ \\
Same Partner & -.006 & 0.03 & -0.19 & 0.84 \\
Chronological age & -.009 & .002 & -3.85 & $.000^{* * *}$ \\
Verbal IQ & -.001 & .001 & -0.85 & 0.39 \\
Non-verbal IQ & -.003 & .002 & -1.33 & 0.18 \\
ASD compared to both TD groups & -0.02 & 0.05 & -0.53 & 0.59 \\
VA compared to MA & -0.11 & 0.05 & -1.99 & $0.04^{*}$ \\
ASD compared to both TD groups: & 0.09 & 0.04 & 2.18 & $0.02^{*}$ \\
Broken Precedent & & & & \\
VA compared to MA: Broken Precedent & 0.21 & 0.05 & 4.10 & $\mathbf{. 0 0 0}^{* * *}$ \\
Table4. Fixed effects in a linear mixed effects model fitting log-transformed RTs of children's response \\
(parameters for a treatment coding of a Group factor) & & &
\end{tabular}

This pattern is clearly associated with the difference in age between two TD groups, as chronological age was a strong predictor of children's rapidity in locating items in all groups in our task. Such a result is not surprising, since age is generally known to significantly affect the speed of both lexical processing and haptic response in young children (Fernald, Perfors, \& Marchman, 2006; Hendrickson, Mitsven, Poulin-Dubois, Zesiger, \& Friend, 2015). Importantly, there were less data points available in the ASD groups due to the higher number of erroneous responses for which RT measures could not be collected. This may also explain why pairwise comparisons did not reveal any substantial difference for RTs in the ASD group relative to either comparison group. 


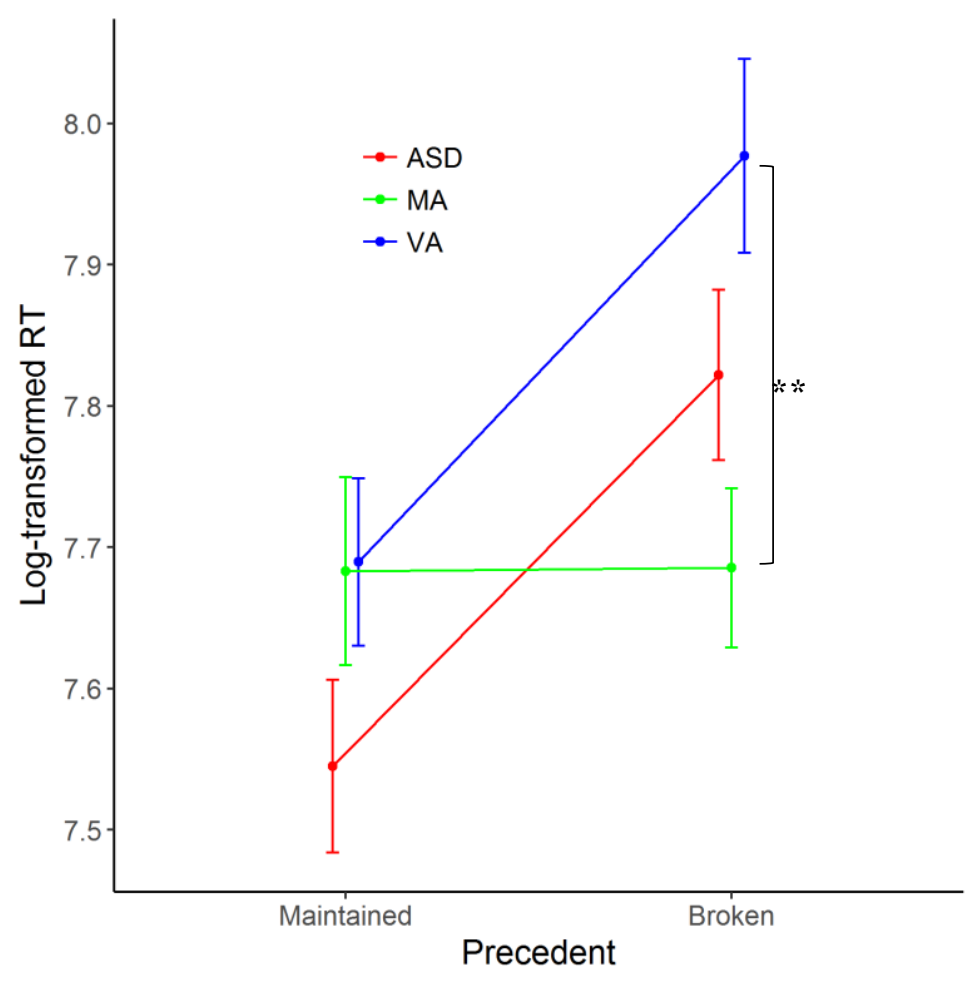

Fig.3 Estimates with standard errors of the linear multilevel regression of reaction times, split by Broken and Maintained precedents, per group

\section{Discussion}

We investigated referential processing in a sample of rather young children with autism (preschoolers and elementary school aged children) in comparison to two groups of TD children, matched according to their verbal age (children from the ASD group on average two years older than children in this group) and to their non-verbal IQ. We detected a deficit in confronting multiple conceptual perspective in autism. Our results also show that this deficit is specific to the ASD diagnosis and cannot entirely be attributed to a receptive language delay. Relative to their TD peers, children with ASD performed poorly at recognizing and interpreting a description that appears in the challenging context of previous entrainment of its semantically related competitor. Maturation of this ability during typical development resulted in almost perfect performance in the MA comparison TD group. Children with ASD were less accurate in interpreting broken precedents both than older TD children in the MA group and younger TD in the VA group.

Interestingly, in a study that compared the ability to suppress the intrusion of previously relevant but currently irrelevant lexical information in children with ASD and children with SLI (Specific Language Impairment), it has been found that children with ASD have a specific 
problem with cognitive flexibility (Marton, Kovi, \& Egri, 2018). Whereas children in SLI group have been shown to display a general difficulty in distinguishing between relevant and irrelevant items, children with ASD have been found to both effectively suppress new irrelevant distractors and struggle with previously entrained distractors. Importantly, this difficulty in dealing with entrained distractors was reflected by a poor performance in children with ASD compared to their TD peers; however, no significant difference in the speed of processing has been detected. This finding stands in full agreement with the results described in the present study.

Our results vindicate our first hypothesis: children with ASD do display difficulty in confronting alternative conceptual descriptions. However, we found no evidence of an implicit tracking of partner perspective, neither by children with ASD nor in the two TD comparison groups. For children in all three groups, delays due to the broken precedent (and not only reaction to maintained precedent) did not depend on the partner's identity (same vs. new). That said, manipulation of partner's identity did prove effective in studies on perspective-taking with adults. In our study, children with and without autism alike lacked sensitivity to their partner's knowledge of previous lexical entrainment. However, it is important to bear in mind that although our stimuli material was similar to the material used in a study with children by Matthews et al., they were different than the kind of stimuli used in those studies, with neurotypical adults, that detected an advantage in processing of broken precedents with a new partner (Brown-Schmidt, 2009; Metzing \& Brennan, 2003). These studies used abstract images as stimuli and thus required speakers to come up with rather specific descriptions (such as The pile of crumbled pebbles / The crushed up bit of cookie crumbs), while we used basic-level nouns, which are likely to be spontaneously used by most speakers (such as cuddly toy/ teddy bear). Such basic-level nouns could bear a weaker association with the conversational partner who introduces them for the first time; for this reason, the probability of detecting any partner-specific cues could be lower for these labels.

That said, it is also possible that even more elaborate and context-specific descriptions would be processed by TD children without relying on a partner's perspective (or not during the early processing stage). That is, the information on one's partner's perspective guides lexical processing in neurotypical adolescents and adults, but not in younger children. Since perspective-taking abilities are deficient, or, at least, strongly delayed, in autism, it is also 
likely that individuals with ASD preferentially process referential descriptions in an egocentric way even at an older age. Our results also clearly suggest that even if individuals with ASD were able to consider their partner's perspective, they would still exhibit difficulties in switching to an alternative descriptions, independently of by whom it was used.

On the one hand, a tendency to reuse referential descriptions entrained in the previous conversational turns may facilitate communication. On the other hand, such automatic alignment on a primed description may turn maladaptive; even though in dialogue, speakers tend to keep the same description for an item, they still must be prepared to shift to a new description. Our results show that children with ASD experience difficulties in shifting to a new conceptual perspective that may arise in such circumstances. This perseveration on a single conceptual perspective may, in turn, generate communicative behaviors that are not optimally tailored to the interactional context.

Difficulty in switching away from a primed referential description to an alternative one may impede new vocabulary acquisition, notoriously delayed in many children with ASD (Loucas et al., 2008; Tager-Flusberg, Paul, \& Lord, 2013). As new words are acquired, they must be integrated within previously established semantic networks. Interestingly, in a study on mutual exclusivity bias in TD children it was found that children's productive vocabulary size positively correlated with parent's natural tendency to introduce alternative descriptions using clarifying connecting information (Callanan \& Sabbagh, 2004). Furthermore, in recent studies comparing patterns of semantic network organization in TD children and in 'late talkers' it was found that children with significant language delay have less cohesively connected lexical networks (Beckage, Smith, \& Hills, 2011; Stella, Beckage, \& Brede, 2017). It is therefore possible that the difficulties children with ASD experience in confronting alternative conceptual perspectives result in poorer integration of newly acquired words. Consistently, in a study comparing sematic networks of children with and without ASD, Shafer et al.(2013) found that children with ASD have sparser and less integrated lexical semantic knowledge.

While our results clearly show that shifting away from one's own conceptual perspectives is problematic for children with ASD, it is nevertheless not impossible, as they accurately processed the broken precedents in $80,5 \%$ of trials (compared to $93,7 \%$ in VA group and $99,9 \%$ in MA group). It is important to notice, however, that since the task was developed for 
rather young children, we decided to use very simple linguistic stimuli to avoid potential biases related to deficits in processing of more complex lexical descriptions. It remains to be seen whether children and adolescents with ASD would exhibit a comparable performance in a task targeting processing of broken precedents with a more complex structure (e.g. combination of adjective and noun) or when the abstract items are labelled using a symbolic play naming to establish precedents (e.g. this triangle will be a doctor).

The difficulty with conceptual flexibility this study unveils in children with ASD probably results from a failure to appropriately suppress more salient, previously entrained, perspective, rather than from a complete lack of representational abilities. In our task, one perspective on the object was created by using the same label several times during the entrainment phase, in a way to enforce a robust association between this label and its referent. Failure to switch away from this salient and primed perspective to a new, but conversationally appropriate one may appear as a socio-pragmatic deficit, owing to an incapacity to consider another person's point of view. However, such referential 'rigidity' could also result from a more general executive deficit, located at the level of inhibition and/or cognitive flexibility (Hill, 2004; Ozonoff, Pennington, \& Rogers, 1991; Russell, Jarrold, \& Hood, 1999; Zelazo \& Mller, 2002). Parallel conclusions can be drawn from studies on nonlinguistic representational abilities in autism. For instance, in the domain of spatial cognition, children with ASD are less likely to spontaneously generate two interpretations of an ambiguous figure, and are more likely to perseverate on a single interpretation (Sobel, Capps, \& Gopnik, 2005). Perseveration on a single perspective may also impact children's disposition to pretense play. Deficit in spontaneous pretend play in autism is well-documented (Charman et al., 1997; Hobson, Hobson, Malik, Bargiota, \& Caló, 2013; Sigman \& Ungerer, 1984), and several authors trace it to children with ASD's incapacity to suppress a salient property of an object in order to assign it a momentary and pretended function\meaning (Jarrold, Carruthers, Smith, \& Boucher, 1994). That is, while failures in communication in autism are often attributed to deficits in Theory of Mind (Baron-Cohen et al., 1985; Eigsti et al., 2011) and/or to lack of social motivation (Chevallier, Kohls, Troiani, Brodkin, \& Schultz, 2012), poor referential flexibility investigated here may stem from deeper executive dysfunction. 


\section{Reference}

Baayen, R. H., Davidson, D. J., \& Bates, D. M. (2008). Mixed-effects modeling with crossed random effects for subjects and items. Journal of Memory and Language, 59(4), 390412. https://doi.org/10.1016/j.jml.2007.12.005

Baron-Cohen, S., Leslie, A. M., \& Frith, U. (1985). Does the autistic child have a "theory of mind" ? Cognition, 21(1), 37-46. https://doi.org/10.1016/0010-0277(85)90022-8

Bates, D. M., Maechler, M., Bolker, B., \& Walker, S. (2015). Fitting linear mixed-effects models using Ime4. Journal of Statistical Software, 67, 1-48. https://doi.org/10.1177/009286150103500418

Beckage, N., Smith, L., \& Hills, T. (2011). Small worlds and semantic network growth in typical and late talkers. PLOS ONE, 6(5), e19348. https://doi.org/10.1371/journal.pone.0019348

Boersma, P. (2001). Praat, a system for doing phonetics by computer. Glot International.

Branigan, H. P., Tosi, A., \& Gillespie-Smith, K. (2016). Spontaneous lexical alignment in children with an autistic spectrum disorder and their typically developing peers. Journal of Experimental Psychology: Learning Memory and Cognition, 42(11), 1821-1831. https://doi.org/10.1037/xIm0000272

Brennan, S. E., \& Clark, H. H. (1996). Conceptual pacts and lexical choice in conversation. Journal of Experimental Psychology: Learning Memory and Cognition, 22(6), 14821493. https://doi.org/10.1037/0278-7393.22.6.1482

Brown-Schmidt, S. (2009). Partner-specific interpretation of maintained referential precedents during interactive dialog. Journal of Memory and Language, 61(2), 171190. https://doi.org/10.1016/j.jml.2009.04.003

Brown-Schmidt, S., Yoon, S. O., \& Ryskin, R. A. (2015). People as contexts in conversation. Psychology of Learning and Motivation - Advances in Research and Theory, 62, 59-99. https://doi.org/10.1016/bs.plm.2014.09.003

Callanan, M. A., \& Sabbagh, M. A. (2004). Multiple labels for objects in conversations with 
young children: Parents' language and children's developing expectations about word meanings. Developmental Psychology, 40(5), 746-763. https://doi.org/10.1037/00121649.40.5.746

Charman, T., Swettenham, J., Baron-Cohen, S., Cox, A., Baird, G., \& Drew, A. (1997). Infants with autism: an investigation of empathy, pretend play, joint attention, and imitation. Developmental Psychology, 33(5), 781-789. https://doi.org/10.1037/00121649.33.5.781

Chevallier, C., Kohls, G., Troiani, V., Brodkin, E. S., \& Schultz, R. T. (2012). The social motivation theory of autism. Trends in Cognitive Sciences, 16(4), 231-238. https://doi.org/10.1016/j.tics.2012.02.007

Colle, L., Baron-Cohen, S., Wheelwright, S., \& Van Der Lely, H. K. J. (2008). Narrative discourse in adults with high-functioning autism or Asperger syndrome. Journal of Autism and Developmental Disorders, 38(1), 28-40. https://doi.org/10.1007/s10803007-0357-5

Deliens, G., Antoniou, K., Clin, E., \& Kissine, M. (2017). Perspective-taking and frugal strategies: Evidence from sarcasm detection. Journal of Pragmatics, 119, 33-45. https://doi.org/10.1016/j.pragma.2017.08.002

Doherty, M., \& Perner, J. (1998). Metalinguistic awareness and theory of mind: Just two words for the same thing? Cognitive Development, 13(3), 279-305. https://doi.org/10.1016/S0885-2014(98)90012-0

Dunn L. M., T.-W. C. M. et D. L. M. (1993). Echelle de vocabulaire en image Peabody. Toronto: Psycan.

Eigsti, I. M., Bennetto, L., \& Dadlani, M. B. (2007). Beyond pragmatics: Morphosyntactic development in autism. Journal of Autism and Developmental Disorders, 37(6), 10071023. https://doi.org/10.1007/s10803-006-0239-2

Eigsti, I. M., De Marchena, A. B., Schuh, J. M., \& Kelley, E. (2011). Language acquisition in autism spectrum disorders: A developmental review. Research in Autism Spectrum Disorders, Vol. 5, pp. 681-691. https://doi.org/10.1016/j.rasd.2010.09.001 
Fernald, A., Perfors, A., \& Marchman, V. A. (2006). Picking up speed in understanding:

Speech processing efficiency and vocabulary growth across the 2 nd year.

Developmental Psychology, 42(1), 98-116. https://doi.org/10.1037/0012-1649.42.1.98

Graham, S. A., \& Madigan, S. (2016). Bridging the Gaps in the Study of Typical and Atypical Cognitive Development: A Commentary. Journal of Cognition and Development, 17(4), 671-681. https://doi.org/10.1080/15248372.2016.1200898

Graham, S. A., Sedivy, J., \& Khu, M. (2014). That's not what you said earlier: Preschoolers expect partners to be referentially consistent. Journal of Child Language, 41(1), 32-48. https://doi.org/10.1017/S0305000912000530

Hendrickson, K., Mitsven, S., Poulin-Dubois, D., Zesiger, P., \& Friend, M. (2015). Looking and touching: What extant approaches reveal about the structure of early word knowledge. Developmental Science, 18(5), 723-735. https://doi.org/10.1111/desc.12250

Hill, E. L. (2004). Evaluating the theory of executive dysfunction in autism. Developmental Review, 24(2), 189-233. https://doi.org/10.1016/j.dr.2004.01.001

Hobson, J. A., Hobson, R. P., Malik, S., Bargiota, K., \& Caló, S. (2013). The relation between social engagement and pretend play in autism. British Journal of Developmental Psychology, 31(1), 114-127. https://doi.org/10.1111/j.2044-835X.2012.02083.x

Jarrold, C., Carruthers, P., Smith, P. K., \& Boucher, J. (1994). Pretend Play: Is It Metarepresentational? Mind \& Language, 9(4), 445-468. https://doi.org/10.1111/j.1468-0017.1994.tb00318.x

Kissine, M. (2012). Pragmatics, cognitive flexibility and autism spectrum disorders. Mind and Language, 27(1), 1-28. https://doi.org/10.1111/j.1468-0017.2011.01433.x

Kronmüller, E., \& Barr, D. J. (2007). Perspective-free pragmatics: Broken precedents and the recovery-from-preemption hypothesis. Journal of Memory and Language, 56(3), 436455. https://doi.org/10.1016/j.jml.2006.05.002

Kronmüller, E., Noveck, I., Rivera, N., Jaume-Guazzini, F., \& Barr, D. (2017). The positive side of a negative reference: The delay between linguistic processing and common ground. Royal Society Open Science, 4(2), 160827. https://doi.org/10.1098/rsos.160827 
Lenth, R. V. (2016). Least-Squares Means: The R Package Ismeans. Journal of Statistical Software, 69(1). https://doi.org/10.18637/jss.v069.i01

Lété, B., Sprenger-Charolles, L., \& Colé, P. (2004). MANULEX: A grade-level lexical database from French elementary school readers. Behavior Research Methods, Instruments, and Computers, 36(1), 156-166. https://doi.org/10.3758/BF03195560

Lord, C., Risi, S., Lambrecht, L., Cook, E. H., Leventhal, B. L., DiLavore, P. C., ... Rutter, M. (2000). Autism Diagnostic Observation Schedule (ADOS). Journal of Autism and Developmental Disorders, Vol. 30, pp. 205-223. https://doi.org/10.1007/BF02211841.

Lord, C., Rutter, M., \& Le Couteur, A. (1994). Autism Diagnostic Interview-Revised: A revised version of a diagnostic interview for caregivers of individuals with possible pervasive developmental disorders. Journal of Autism and Developmental Disorders, 24(5), 659685. https://doi.org/10.1007/BF02172145

Loucas, T., Charman, T., Pickles, a, Simonoff, E., Chandler, S., Meldrum, D., \& Baird, G. (2008). Autistic symptomatology and language ability in autism spectrum disorder and specific language impairment. Journal of Child Psychology and Psychiatry, 49, 11841192. https://doi.org/DOI 10.1111/j.1469-7610.2008.01951.x

Markman, E. M., \& Wachtel, G. F. (1988). Children's use of mutual exclusivity to constrain the meanings of words. Cognitive Psychology, 20(2), 121-157. https://doi.org/10.1016/0010-0285(88)90017-5

Marton, K., Kovi, Z., \& Egri, T. (2018). Is interference control in children with specific language impairment similar to that of children with autistic spectrum disorder? Research in Developmental Disabilities, 72, 179-190. https://doi.org/10.1016/j.ridd.2017.11.007

Matthews, D., Lieven, E., \& Tomasello, M. (2010). What's in a Manner of Speaking? Children's Sensitivity to Partner-Specific Referential Precedents. Developmental Psychology, 46(4), 749-760. https://doi.org/10.1037/a0019657

Metzing, C., \& Brennan, S. E. (2003). When conceptual pacts are broken: Partner-specific effects on the comprehension of referring expressions. Journal of Memory and Language, 49(2), 201-213. https://doi.org/10.1016/S0749-596X(03)00028-7 
Nadig, A., Seth, S., \& Sasson, M. (2015). Global similarities and multifaceted differences in the production of partner-specific referential pacts by adults with autism spectrum disorders. Frontiers in Psychology, 6(DEC). https://doi.org/10.3389/fpsyg.2015.01888

Nilsen, E. S., \& Fecica, A. M. (2011). A model of communicative perspective-taking for typical and atypical populations of children. Developmental Review, Vol. 31, pp. 55-78. https://doi.org/10.1016/j.dr.2011.07.001

Ozonoff, S., Pennington, B. F., \& Rogers, S. J. (1991). Executive Function Deficits in HighFunctioning Autistic Individuals: Relationship to Theory of Mind. Journal of Child Psychology and Psychiatry, 32(7), 1081-1105. https://doi.org/10.1111/j.14697610.1991.tb00351.x

Perkins, M. R., Dobbinson, S., Boucher, J., Bol, S., \& Bloom, P. (2006). Lexical Knowledge and Lexical Use in Autism. J Autism Dev Disord, 795-805. https://doi.org/DOI $10.1007 / \mathrm{s} 10803-006-0120-3$

Perner, J., Stummer, S., Sprung, M., \& Doherty, M. (2002). Theory of mind finds its Piagetian perspective: Why alternative naming comes with understanding belief. Cognitive Development, 17(3-4), 1451-1472. https://doi.org/10.1016/S0885-2014(02)00127-2

Pickering, M. J., \& Garrod, S. (2004). Toward a mechanistic psychology of dialogue. Behavioral and Brain Sciences, 27(02), 169-190; discussion 190-226. https://doi.org/10.1017/S0140525X04000056

R Core Team. (2017). A Language and Environment for Statistical. Www. R-Project. Org, p. 900051. https://doi.org/citeulike-article-id:2400517

Rapin, I., \& Dunn, M. (2003). Update on the language disorders of individuals on the autistic spectrum. Brain and Development, Vol. 25, pp. 166-172. https://doi.org/10.1016/S0387-7604(02)00191-2

Roid, G., Miller, L., Pomplun, \& Koch. (2013). Leiter International Performance Scale. Stoelting Company, Wood Dale, IL 60191 USA.

Russell, J., Jarrold, C., \& Hood, B. (1999). Two intact executive capacities in children with autism: Implications for the core executive dysfunctions in the disorder. Journal of 
Autism and Developmental Disorders, 29(2), 103-112.

https://doi.org/10.1023/A:1023084425406

Schafer, G., Williams, T. I., \& Smith, P. T. (2013). Which words are hard for autistic children to learn? Mind and Language, 28(5), 661-698. https://doi.org/10.1111/mila.12038

Sigman, M., \& Ungerer, J. A. (1984). Cognitive and language skills in autistic, mentally retarded, and normal children. Developmental Psychology, 20(2), 293-302.

https://doi.org/10.1037/0012-1649.20.2.293

Slocombe, K. E., Alvarez, I., Branigan, H. P., Jellema, T., Burnett, H. G., Fischer, A., ... Levita, L. (2013). Linguistic alignment in adults with and without Asperger's syndrome. Journal of Autism and Developmental Disorders, 43(6), 1423-1436.

https://doi.org/10.1007/s10803-012-1698-2

Sobel, D. M., Capps, L. M., \& Gopnik, A. (2005). Ambiguous figure perception and theory of mind understanding in children with autistic spectrum disorders. British Journal of Developmental Psychology, 23(2), 159-174.

https://doi.org/10.1348/026151004X20694

Stella, M., Beckage, N. M., \& Brede, M. (2017). Multiplex lexical networks reveal patterns in early word acquisition in children. Scientific Reports, 7. https://doi.org/10.1038/srep46730

Tager-Flusberg, H., Paul, R., \& Lord, C. (2013). Language and Communication in Autism. In Handbook of Autism and Pervasive Developmental Disorders (pp. 335-364). https://doi.org/10.1002/9780470939345.ch12

Zelazo, P. D., \& Mller, U. (2002). Executive Function in Typical and Atypical Development. In Blackwell Handbook of Childhood Cognitive Development (pp. 445-469). https://doi.org/10.1002/9780470996652.ch20 